\title{
Glaucoma: Past, Present, and Future
}

\section{Glaucoma: Passado, Presente e Futuro}

\author{
Sebastião Cronemberger ${ }^{1}$ https://orcid.org/0000-0003-1466-9963 \\ 'Professor Titular de Oftalmologia - Faculdade de Medicina - UFMG - Belo Horizonte - MG - Brazil.
}

$\mathbf{P}$ rimary open-angle glaucoma (POAG) is an age-old disease that remains enigmatic. Millions of people worldwide still lose their sight due to POAG and the prediction is that, with longer life expectancy, more people will be diagnosed with it. ${ }^{(1)}$

Over the years, glaucoma has undergone changes in concept, workup and treatment. Up to now, the concept of this disease is not consensual. ${ }^{(2)}$ Would it be a brain disease? Initially, glaucoma was synonymous with elevated intraocular pressure (IOP). The elevated IOP would cause the excavation of the optic disc (glaucomatous excavation) ${ }^{(3)}$ and visual field (VF) loss, characterizing the glaucoma triad. ${ }^{(2)}$ Conceptual changes occurred in 1996 when glaucoma was defined as an optic neuropathy being the elevated IOP its main risk factor. ${ }^{(4)}$ Since then, optic neuropathy and VF loss characterize the manifest glaucoma. However, some patients may have an elevated IOP without VF loss nor retinal nerve fiber layer

(RNFL) loss - ocular hypertension (OH). ${ }^{(5)}$ Others may present preperimetric glaucoma characterized by RNFL loss detected by optical coherence tomography (OCT) in the absence of VF loss. ${ }^{(6)}$ It is surprising that elevated IOP, the only known modifiable condition, has been considered as the principal risk factor taking in view that, for avoiding glaucoma progression, the treatment is the IOP normalization even when IOP is statistically normal. It is a big mistake to think that the IOP level is important for POAG and normal tension glaucoma treatment, but at the same time, not as a criterion for its diagnosis. It is known that elevated IOP is the result of impairment of drainage of the aqueous humor (AH) independently of the type of glaucoma. Uncontrolled IOP causes glaucoma progression with irreversible and progressive loss of RNFL and VF. This implies that elevated IOP seems to be or is a fundamental part of the disease and needs a detailed investigation. Taking into consideration that IOP is a highly dynamic parameter with many influence factors, it is an absurd to manage glaucoma with single IOP measurement. The major challenge is to find out the target IOP for each preperimetric or glaucomatous patient.

\section{Workup}

The workup of glaucoma has also changed over time. New tonometers have appeared, but none of them has overcome the gold standard Goldmann applanation tonometer since 1957. (7) In 1997, the measurement of central corneal thickness (CCT) was introduced, but there is no algorithm that directly relates it to the value of $\mathrm{IOP}^{(8,9)}$ Also, the role of corneal hysteresis $(\mathrm{CH})$ in glaucoma has not been fully elucidated. $\mathrm{CH}$ may be more significantly associated with glaucoma than CCT.(10)

OCT and OCT angiography (OCTA) have been used in last decades. ${ }^{(11,12)}$ Diniz-Filho et al. reported that "higher levels of IOP during follow-up were associated with faster rates of RNFL loss over time measured by SD OCT".(10) OCTA allows for simultaneous in vivo imaging of the morphology and vasculature of the eye. ${ }^{(12)}$

\section{IOP assessment}

The 24-hour IOP investigation still remains a challenge. It is performed for detecting IOP peaks but it is not performed by most ophthalmologists around the world because of expense and inconvenience. ${ }^{(12)}$

Many provocative and functional tests have been used to diagnose early glaucoma. The water-drinking and ibopamine tests failed to diagnose early POAG because of high rates of false-positive and false-negative results. ${ }^{(13,14)}$ Some authors have monitored 24-hour IOP with the SENSIMED Triggerfish contact lens, but the results are not convincing yet.(15)

\section{Corneal hysteresis $(\mathbf{C H})$ and lamina cribrosa}

Although there are some controversies about $\mathrm{CH}$ in glaucoma, some authors reported that lower $\mathrm{CH}$ measurements were significantly associated with increased risk of developing glaucomatous visual field defects over time.(10) Studies using Swept-Source OCT (SS-OCT) have demonstrated that the lamina cribrosa is likely biomechanically active and that significant changes occur in glaucoma. ${ }^{(16)}$

\section{VF examination}

In the past, blue-yellow perimetry was performed for early glaucoma diagnosis. This technique was completely abandoned. (14) Frequency-doubling perimetry (FDP) has been less used than in thepast, presenting a tendency of abandon. ${ }^{(14)}$ Nowadays, all scientific works use the 24-2 test VF.

Recently, some authors have advised performing the 10-2 test could be essential for some glaucoma patients. ${ }^{(17)}$ Other authors reported that further studies are needed to determine the potential advantages of the 10-2 test in relation to the 24-2. ${ }^{(18)}$ 


\section{Electrophysiology} of POAG. ${ }^{(19)}$

Currently, no definitive indications of electrophysiology have been established either at early detection or during follow-up

\section{Genetics}

Inheritance in glaucoma is multifactorial polygenic. Currently, 127 genes are associated with POAG. However, more researches are needed to identify new genes and disease-causing mutations. ${ }^{(20)}$

\section{Clinical treatment}

In spite of great progress in recent decades, no topical medication for glaucoma treatment is considered ideal. ${ }^{(21)}$ Topical medications currently in use are directed toward reducing AH production and not to improve the AH drainage via trabecular meshwork (TM). A great problem is poor adherence) and uncertainty exists about which glaucoma suspects should be treated.(22)

\section{Laser treatment}

Selective laser trabeculoplasty (SLT) is as effective for lowering IOP as argon laser trabeculoplasty (ALT) and topical medication in POAG/OH patients. ${ }^{(23)}$ It can be used as an option for primary POAG treatment or adjunct treatment and has effect in other glaucoma subtypes. Both laser modalities have similar success and safety but SLT is better tolerated by patients. ${ }^{(23)}$ SLT is repeatable, causing minimal damage to the TM. Adverse events are uncommon but most of these are transient and self-limiting. SLT is associated with better quality of life.

\section{MicroPulse transscleral cyclophotocoagulation}

It is a novel technique that uses repetitive micropulses of active diode laser (On cycles) interspersed with resting intervals (Off cycles). ${ }^{(24)}$ It has been proposed that the OFF cycles allow thermal dissipation and, therefore, reduce collateral damage. The literature suggests that Micropulse has a better safety profile compared to traditional continuous-wave cyclophotocoagulation. Until now, there are no clear guidelines stating the ideal laser parameters that would allow the best balance between high and sustained effectiveness with minimal side effects. No research control trial is still available.

\section{Surgical treatment}

Trabeculectomy with adjunctive mitomycin C continues to be the gold standard incisional surgery for POAG. Glaucoma drainage implants (GDI) have improved the surgical prognosis for refractory glaucoma. Most used implants are non-restrictive (Molteno and Baerveldt implants) and flow-restrictive (Ahmed Valve). Growth of utilization of GDI has dramatically increased in recent years and their complications have been reduced. ${ }^{(25)}$

\section{Micro-invasive glaucoma surgery (MIGS)}

In a recent work, published in this periodical, Guedes concludes that "Given what MIGS offers and what the results attest, there is room for these techniques to be used safely and effectively. Therefore, it is worth going deeper on the theoretical and practical knowledge of these innovative surgical techniques". ${ }^{(26)}$ However, randomized clinical trials with long-term follow-up remain necessary to evaluate the efficacy and late complications of these novel procedures. Gonioscopy-assisted Transluminal Trabeculotomy (GATT) seems promising in POAG. ${ }^{(27)}$

\section{Neuroprotection}

There are no available neuroprotector drugs yet. Memantine has failed to slow or prevent glaucoma progression in a multicenter study with 126 centers. ${ }^{(28)}$ Beyond IOP control, better treatments for glaucoma should include: neuroprotection, regeneration and neuroenhancement. At this time, no scientific evidence-based drug is available. There are four Research Control Trials in phases 1 and 2 , studying these needs in glaucoma. ${ }^{(20)}$

\section{Intraocular stem cell therapy}

The Food Drug Administration (FDA) is investigating unlicensed clinics that offer unapproved stem cell therapy and taking appropriate regulatory actions. These treatments require further scientific evaluation to assure their safety and effectiveness to the public in well-conducted clinical trials under the aegis of the FDA. Stem cell therapy may become a promising treatment in the future. ${ }^{(29)}$

\section{Glaucoma and oral medications}

It is extremely necessary to be careful with the prescription of topical antiglaucoma medications for patients with asthma, cardiac and renal diseases. Similarly, it is important to take into consideration the possible side effects of topical and systemic corticosteroids and overdose of oral moxifloxacin. ${ }^{(30)}$ Overdose of moxifloxacin can cause a bilateral secondary open-angle glaucoma by acute depigmentation of the iris. ${ }^{(31)}$

\section{Future}

\section{IOP, OCT, OCTA and Swept-Source OCT (SS-OCT) correlation}

There is need to investigate the correlation between 24-hour IOP peaks and fluctuations and glaucomatous damage shown by OCT, OCTA and SS-OCT. ${ }^{(32,33)}$ 


\section{Machine Learning}

One important tool which is beginning to be tested and will be used in the future is deep learning networks. Researchers can be trained, for example, to quantify the amount of neuroretinal damage on optic disc photographs using SD-OCT Bruch's membrane opening minimum rim width (BMO-MRW) as a reference and find out algorithms that show high accuracy for glaucoma detection. ${ }^{(34,35)}$ Others researchers are trying to predict the timing of surgical interventions, central VF measures e automate GAT. ${ }^{(36,37)}$

\section{Clinical treatment}

In the last two decades, some authors have shown that Rho kinase inhibitors reduce IOP by increasing AH drainage through the TM. In addition, Rho kinase inhibitors also enhance retinal ganglion cell survival after ischemic injury and increase ocular blood flow. ${ }^{(38,39)}$

\section{Drug delivery for glaucoma and Biomarkers}

Several options will likely become available in the near future to ease the burden of daily and chronic topical administration of antiglaucoma drugs. ${ }^{(40)}$ Bimatoprost SR has shown favorable efficacy and safety profiles up to 24 months and may represent a transformational new approach to glaucoma therapy. ${ }^{(41)}$

In an ongoing Phase 3 study, initial 1-year results show lower VF progression in POAG in eyes after administration of BimSR than in eyes receiving topical timolol. The authors suggest a possible benefit from sustained drug delivery in VF preservation. ${ }^{(42)}$

Recently, a novel technology called Detection of Apoptosing Retinal Cells (DARC) allows real-time in vivo quantification of apoptosing cells through the use of a fluorescent biomarker and a confocal scanning ophthalmoscope. The results suggest that DARC may have potential in vivo quantification of apoptosing cells which could help alleviate the medical, social, and economic burden associated with this blinding condition. ${ }^{(43)}$

\section{Final considerations}

The majority of patients with glaucoma are unaware that they have the disease. Therefore, to increase the proportion of diagnosed glaucoma patients the following steps are necessary: national programs that promote eye care; community programs that offer eye exams and education and more eye care services in rural areas. In addition, there is a need for homogeneous evidence-based guidelines for glaucoma management and standardized workup worldwide. The adoption of common standards in developing clinical practice guidelines in ophthalmology, and specifically in glaucoma, should improve their consistency and quality. ${ }^{(22)}$

In summary, to manage glaucoma, it is necessary to adequately investigate IOP and mainly to perform structural and functional tests, regardless of ocular damage.

\section{REFERENCES}

1. Quigley HA. 21st century glaucoma care. Eye (Lond).2019;33(2):254 60 .

2. Iyer J,Vianna JR, Chauhan BC, Quigley HA. Toward a new definition of glaucomatous optic neuropathy for clinical research. Curr Opin Ophthalmol. 2020;31(2):85-90.

3. Quigley HA, Green WR. The histology of human glaucoma cupping and optic nerve damage: clinicopathologic correlation in 21 eyes. Ophthalmology. 1979;86(10):1803-30.

4. Straatsma BR. Centenary of the Japanese Ophthalmological Society and the American Academy of Ophthalmology. Am J Ophthalmol. 1996;121(5):568-9.

5. Brandt JD, Beiser JA, Kass MA, Gordon MO; Ocular Hypertension Treatment Study (OHTS) Group. Central corneal thickness in the Ocular Hypertension Treatment Study (OHTS). Ophthalmology. 2001;108(10):1779-88.

6. Daga FB, Gracitelli CP, Diniz-Filho A, Medeiros FA. Is vision-related quality of life impaired in patients with preperimetric glaucoma? $\mathrm{Br}$ J Ophthalmol. 2019;103(7):955-9.

7. Goldmann H,Schmidt T. [Applanation tonometry]. Ophthalmologica. 1957;134(4):221-42.

8. Herndon LW, Choudhri SA, Cox T, Damji KF, Shields MB, Allingham RR. Central corneal thickness in normal, glaucomatous, and ocular hypertensive eyes. Arch Ophthalmol. 1997;115(9):1137-41.

9. Doughty MJ,Zaman ML. Human corneal thickness and its impact on intraocular pressure measures: a review and meta-analysis approach. Surv Ophthalmol. 2000;44(5):367-408.
10. Susanna CN, Diniz-Filho A, Daga FB, Susanna BN, Zhu F, Ogata NG, et al. A Prospective Longitudinal Study to Investigate Corneal Hysteresis as a Risk Factor for Predicting Development of Glaucoma. Am J Ophthalmol. 2018;187(3):148-52.

11. van Velthoven ME, Faber DJ, Verbraak FD, van Leeuwen TG, de Smet MD. Recent developments in optical coherence tomography for imaging the retina. Prog Retin Eye Res. 2007;26(1):57-77.

12. Diniz-Filho A, Abe RY, Zangwill LM, Gracitelli CP, Weinreb RN, Girkin CA, et al. Association between Intraocular Pressure and Rates of Retinal Nerve Fiber Layer Loss Measured by Optical Coherence Tomography. Ophthalmology. 2016;123(10):2058-65.

13. Cronemberger S, Silva AC, Calixto N. Importance of intraocular pressure measurement at 6:00 a.m. in bed and in darkness in suspected and glaucomatous patients. Arq Bras Oftalmol. 2010;73(4):346-9.

14. Cronemberger S, Calixto N, Vieira Filho HM, Souza TT, Souza CA, Gomes RA. Provocative tests, functional exams and daily curve of intraocular pressure in glaucoma suspects. Vis Pan-Am. 2012;11(3):80-4.

15. Beltran-Agulló L, Buys YM, Jahan F, Shapiro CM, Flanagan JG, Cheng J, et al. Twenty-four-hour intraocular pressure monitoring with the SENSIMED Triggerfish contact lens: effect of body posture during sleep. Br J Ophthalmol. 2017;101(10):1323-8.

16. Takusagawa HL, Hoguet A, Junk AK, Nouri-Mahdavi K, Radhakrishnan S, Chen TC. Swept-Source OCT for Evaluating the Lamina Cribrosa: A Report by the American Academy of Ophthalmology. Ophthalmology. 2019;126(9):1315-23. 
17. De Moraes CG, Hood DC, Thenappan A, Girkin CA, Medeiros FA, Weinreb RN, et al. 24-2 Visual fields miss central defects shown on 10-2 tests in glaucoma suspects, ocular hypertensives, and early glaucoma. Ophthalmology. 2017;124(10):1449-56.

18. Wu Z, Medeiros FA, Weinreb RN, Zangwill LM. Performance of the 10-2 and 24-2 visual field tests for detecting central visual field abnormalities in glaucoma. Am J Ophthalmol. 2018;196(12):10-7.

19. Senger C, Moreto R, Watanabe SE, Matos AG, Paula JS. Electrophysiology in glaucoma. J Glaucoma. 2020;29(2):147-53.

20. Miller MA, Fingert JH, Bettis DI. Genetics and genetic testing for glaucoma. Curr Opin Ophthalmol. 2017;28(2):133-8.

21. Calixto N, Cronemberger S. Objetivo terapéutico: el antiglaucomatoso ideal. Alcon Laboratorios. Terapéutica Médica del Glaucoma; su perspectiva para la década del 90. Buenos Aires: Alcon Laboratorios; 1990. p. 10-7.

22. Ou Y, Goldberg I, Migdal C, Lee PP. A critical appraisal and comparison of the quality and recommendations of glaucoma clinical practice guidelines. Ophthalmology. 2011;118(6):1017-23.

23. Garg A, Gazzard G. Selective laser trabeculoplasty: past, present, and future. Eye (Lond). 2018;32(5):863-76.

24. Sanchez FG, Peirano-Bonomi JC, Grippo TM. Micropulse transscleral cyclophotocoagulation: a hypothesis for the ideal parameters. Med Hypothesis Discov Innov Ophthalmol. 2018;7(3):94-100.

25. Chatzara A, Chronopoulou I, Theodossiadis G, Theodossiadis P, Chatziralli I. XEN implant for glaucoma treatment: a review of the literature. Semin Ophthalmol. 2019;34(2):93-7.

26. Guedes RA. Micro-invasive glaucoma surgeries. Are they worth it? Rev Bras Oftalmol. 2019;78(4):217-8.

27. Rahmatnejad K, Pruzan NL, Amanullah S, Shaukat BA, Resende AF, Waisbourd M, et al. Surgical outcomes of gonioscopy-assisted transluminal trabeculotomy (GATT) in patients with open-angle glaucoma. J Glaucoma. 2017;26(12):1137-43.

28. Weinreb RN, Liebmann JM, Cioffi GA, Goldberg I, Brandt JD, Johnson CA, et al. Oral memantine for the treatment of glaucoma: design and results of 2 randomized, placebo-controlled, phase 3 studies. Ophthalmology. 2018;125(12):1874-85.

29. Harrell CR, Fellabaum C, Arsenijevic A, Markovic BS, Djonov $\mathrm{V}$, Volarevic V. Therapeutic potential of mesenchymal stem cells and their secretome in the treatment of glaucoma. Stem Cells Int. 2019;2019:7869130.

30. Ang M, Tan AC, Cheung CM, Keane PA, Dolz-Marco R, Sng CC, et al. Optical coherence tomography angiography: a review of current and future clinical applications. Graefes Arch Clin Exp Ophthalmol. 2018;256(2):237-45.

31. Maestrini HA, Maestrini AA, Machado DO, Santos DV, Almeida HG. Bilateral acute depigmentation of the iris (BADI): first reported case in Brazil. Arq Bras Oftalmol. 2013;76(1):42-4.
32. Verticchio Vercellin AC, Harris A, Tanga L, Siesky B, Quaranta L, Rowe LW, et al. Optic nerve head diurnal vessel density variations in glaucoma and ocular hypertension measured by optical coherence tomography angiography. Graefes Arch Clin Exp Ophthalmol. 2020;10.1007/s00417-020-04635-6.

33. Chen TC, Hoguet A, Junk AK, Nouri-Mahdavi K, Radhakrishnan S, Takusagawa HL, et al. Spectral-domain OCT: helping the clinician diagnose glaucoma: a report by the American Academy of Ophthalmology. Ophthalmology. 2018;125(11):1817-27.

34. Li Z, He Y, Keel S, Meng W, Chang RT, He M. Efficacy of a deep learning system for detecting glaucomatous optic neuropathy based on color fundus photographs. Ophthalmology. 2018;125(8):1199-206.

35. Thompson AC, Jammal AA, Medeiros FA. A deep learning algorithm to quantify neuroretinal rim loss from optic disc photographs. Am J Ophthalmol. 2019;201(5):9-18.

36. Dharia RS, Li Y, Saha R, Buys Y, Trope G, Eizenmam M. Prediction glaucoma interventions with deep learning networks [abstract]. AGS Annual Meeting, 2020. p. 84.

37. Mohhmmadzadeh V, Sahin S, Hassan O, Mylavarapu A, Marttinyan J, Fu Q, et al. Prediction of central visual field measures from macular OCT images with deep learning [abstract]. AGS Annual Meeting, 2020. p. 85.

38. Rao VP, Epstein DL. Rho GTPase/Rho kinase inhibition as a novel target for the treatment of glaucoma. BioDrugs. 2007;21(3):167-77.

39. Maruyama Y, Ikeda Y, Mori K, Yoshii K, Ueno M, Sotozono C, et al. Safety and efficacy of long-term ripasudil $0.4 \%$ instillation for the reduction of intraocular pressure in japanese open-angle glaucoma patients. J Ocul Pharmacol Ther. 2020;10.1089/jop.2019.0125.

40. Aref AA. Sustained drug delivery for glaucoma: current data and future trends. Curr Opin Ophthalmol. 2017;28(2):169-74.

41. Lee SS, Dibas M, Almazan A, Robinson MR. Dose-Response of Intracameral Bimatoprost Sustained-Release Implant and Topical Bimatoprost in Lowering Intraocular Pressure. J Ocul Pharmacol Ther. 2019;35(3):138-44.

42. Medeiros F, Bejanian M, Goodkin M, Wang K, Zangh J, Robinson M, et al. Visual field outcomes in open-angle glaucoma patients treated with Bimatoprost SR in Phase 3: results at primary database lock [abstract]. AGS Annual Meeting, 2020. p. 98.

43. Yang E, Al-Mugheiry TS, Normando EM, Cordeiro MF. Real-time imaging of retinal cell apoptosis by confocal scanning laser ophthalmoscopy and its role in glaucoma. Front Neurol. 2018 May 15;9:338. doi: 10.3389/fneur.2018.00338.

\section{Corresponding author:}

E-mail: secronem@gmail.com 